\title{
The relationship of hospital admission and fatality from myocardial infarction to glycohaemoglobin levels
}

\author{
J.S. Yudkin ${ }^{1}$, G. A. Oswald ${ }^{1}$, P.M. McKeigue ${ }^{2}$, R. D. Forrest ${ }^{1}$ and C. A. Jackson ${ }^{1}$ \\ ${ }^{1}$ Academic Unit of Diabetes and Endocrinology of the Department of Medicine, and \\ ${ }^{2}$ Department of Community Medicine, University College \& Middlesex School of Medicine, London, UK
}

\begin{abstract}
Summary. We have performed a study to assess the relative contributions of increased hospital admission rates with acute myocardial infarction and increased hospital case fatality to the excess mortality of subjects with elevated levels of glycohaemoglobin from myocardial infarction. Glycohaemoglobin levels were estimated by isoelectric focussing in 397 subjects without known diabetes mellitus admitted with myocardial infarction and compared with a control population reconstructed from a community sample of 1084 subjects without known diabetes mellitus screened in general practice. In the case-control comparison, glycohaemoglobin levels above the 90th centile were associated with relative
\end{abstract}

risks of 3.1 (95\% confidence interval 1.4-6.8) for admission with myocardial infarction and 5.3 (95\% confidence interval 2.1-13.4) for death in hospital. Elevated glycohaemoglobin on admission was a predictor of both death and cardiac pump failure among those admitted with myocardial infarction, as was the presence of known diabetes. In those over 40 years of age, the top $1 \%$ of the glycohaemoglobin distribution contribute $4.3 \%$ of admissions and $9.6 \%$ of hospital deaths with myocardial infarction.

Key words: Coronary heart disease, acute myocardial infarction, glycohaemoglobin, cardiogenic shock.
Diabetic patients have higher mortality from coronary heart disease than the general population [1-4]. In some studies, those with lesser degrees of glucose intolerance share this excess mortality [2]. Diabetic patients admitted to hospital after acute myocardial infarction (AMI) fare poorly, with case fatality 1.5 to 2 -fold higher than in non-diabetic subjects with AMI [5], but the relative contributions of excess incidence of, and excess case fatality from, AMI to the increased mortality of diabetes have not been clearly defined. Indeed, if it could be shown that increased case fatality makes a major contribution to coronary heart disease mortality, then interventions in patients admitted with AMI such as improved control of blood-glucose [6] or a combination of streptokinase and aspirin [7] might be expected to play an important role in reducing total coronary heart disease mortality in diabetic patients.

We have reported that in patients without known diabetes who are admitted to hospital after AMI, raised admission levels of glycohaemoglobin are associated with an increase in hospital mortality [8], suggesting that subjects with undiagnosed diabetes, and perhaps also those with lesser degrees of glucose intolerance, share this risk with patients with known diabetes. We now report the results of a case control study to determine (1) the relative risk of admission to hospital with AMI of subjects without known diabetes who have elevated levels of glycohaemoglobin, and (2) the relative risk of these patients developing pump failure or dying in hospital following admission with AMI.

\section{Subjects and methods}

Between November 1982 and October 1984, 463 patients with AMI, confirmed according to WHO criteria [9] were admitted to the Whittington Hospital. All local general practitioners refer patients with chest pain suggestive of myocardial infarction to hospital, and the acute services catchment population of the hospital is clearly defined. Sixty-six of the admitted patients had known diabetes $(14 \%$ of the total). These subjects had predominantly Type 2 (non-insulin-dependent) diabetes, with only $11 / 66(17 \%)$ on treatment with insulin, and only 4 of these were Type 1 (insulin-dependent) as evidenced by ketosis and weight loss. The diagnosis of diabetes mellitus was confirmed either by the finding of an elevated level of glycohaemoglobin $\left(\mathrm{HbA}_{1 \mathrm{c}}>8.0 \%\right)$ or by confirming that the diagnostic criteria employed satisfied those of the WHO Study Group Report [10]. In the remaining 397 subjects without known diabetes mellitus, all of whom were older than 40 years of age, a blood sample was taken for estimation of glycohaemoglobin using an isoelectric focussing technique ( $\mathrm{LKB}$, Bromma, Sweden) with the exclusion of the pre- $\mathrm{A}_{1 \mathrm{c}}$ band $\left(\mathrm{HbA}_{1 c}\right)$ [11]. Pump failure was defined as a systolic blood pressure of $<90 \mathrm{~mm} \mathrm{Hg}$ with clinical signs of hypoperfusion, and/or 
clinical or radiological signs of pulmonary oedema, unassociated with severe bradycardia (pulse rate $<50 / \mathrm{min}$ ). Because the case series comprised patients admitted to hospital with myocardial infarction, it was not possible accurately to document pre-morbid blood pressure or cholesterol levels.

Between July 1983 and July 1984, a community diabetic screening survey was conducted in a group practice within the hospital's catchment area [12]. The practice is representative of the population of the total catchment area in terms of social class and ethnic origin [13]. In particular, there were similar numbers of subjects in low and high coronary heart disease risk groups between the subjects studied and the catchment population. Thus the proportion of subjects in social classes $I$ and $V$ [14] were $3.5 \%$ and $8.8 \%$, respectively, in the study population, and $5.8 \%$ and $6.1 \%$ in the catchment population. The proportion of Asian, Mediterranean and other European, and Afrocaribbean subjects respectively was $1.8 \%, 10.0 \%$ and $9.6 \%$ in the practice population studied and $2.8 \%, 9.0 \%$ and $8.5 \%$ in the catchment population. A random sample of 1084 subjects older than 40 years of age was screened by a single capillary blood glucose level $2 \mathrm{~h}$ after a $75 \mathrm{~g}$ glucose load and an estimation of glycohaemoglobin using an agar gel electrophoresis technique (Corning Medical Ltd., Halstead, Essex, UK) [15]. Subjects were ranked according to their levels of both glycohaemoglobin and $2 \mathrm{~h}$ blood glucose into separate strata. A stratified sample of 347 subjects was selected for recall, comprising all subjects with levels of either glycohaemoglobin or $2 \mathrm{~h}$ blood glucose above the 90 th centile, $50 \%$ of those with levels of either variable between the 80 th and 90 th centiles (but excluding those in the top stratum), $25 \%$ of those with levels of either variable between the 50th and 80th centiles (but excluding those in the top 2 strata) and $10 \%$ of those with levels of both variables below the 50th centile. Two hundred twenty-three subjects $(64.3 \%)$ attended for recall, the proportion not differing significantly between the recall strata $\left(\chi^{2}=1.06,3 \mathrm{df}, p>0.7\right)$. At recall examination, a full glucose tolerance test was performed and glycohaemoglobin was estimated both by agar gel electrophoresis, as used at screening, and by isoelectric focussing with exclusion of the pre- $\mathrm{A}_{1 \mathrm{c}}$ band $\left(\mathrm{HbA}_{1 \mathrm{c}}\right)$ [11]. These results were available on 210 subjects of the 223 who attended the recall examination $[16,17]$.

The normal range in our laboratory for glycohaemoglobin estimation by agar gel electrophoresis is $6.5-8.5 \%$, and by iso-electric focussing $6.1-7.8 \%$. The within and between assay coefficents of variation are $3.9 \%$ and $6.2 \%$, respectively, for agar gel electrophoresis and $4.9 \%$ and $5.3 \%$ for iso-electric focussing.

\section{Statistical analysis}

In order to assess the risks of admission and mortality in subjects with abnormal levels of glycohaemoglobin, we have calculated relative risks at 2 different cut-off levels rather than employing $\mathrm{HbA}_{1 \mathrm{c}}$ as a continuous variable. The cut-off levels of $\mathrm{HbA}_{1 \mathrm{c}}$ employed in the case-control analysis were $6.9 \%$ and $7.8 \%$ which represent, respectively, the 90th centile of the normal range and $+3 \mathrm{SD}$ from the mean. We have previously demonstrated that a level of $\mathrm{HbA}_{1 \mathrm{c}}>$ $7.8 \%$ in subjects admitted with AMI is $100 \%$ sensitive and $99 \%$ specific for overt diabetes mellitus with fasting hyperglycaemia at 3-months follow-up, while impaired glucose tolerance is significantly more frequent in subjects with levels of $6.9 \%-7.8 \%(p<0.001)$ [18]. Among 22 survivors of myocardial infarction with levels of $\mathrm{HbA}_{1 \mathrm{c}}$ of $6.9 \%-7.8 \%$, none had diabetes mellitus with fasting hyperglycaemia at 3-months follow up [18].

Case series. After stratifying by sex and 10-year age groups the risks of pump failure and death were calculated for each level of $\mathrm{HbA}_{1 \mathrm{c}}$ and for the patients with known diabetes, standardised on the age distribution of the subjects without known diabetes mellitus. Odds ratios, comparing the two highest levels of $\mathrm{HbA}_{1 \mathrm{c}}$ and those with known diabetes, with the lowest $\mathbf{H b A}_{1 \mathrm{c}}$ level, were calculated by standard methods $[19,20]$.
Case control study. Relative risks of admission with AMI have beer calculated for subjects in each of the two highest $\mathrm{HbA}_{1 \mathrm{c}}$ bands com. pared with the lowest. The population screening study employed agar gel electrophoresis to estimate glycohaemoglobin levels or 1084 subjects. The stratified sample at recall had levels of glycohaemoglobin estimated by isoelectric focussing $\left(\mathrm{HbA}_{1 \mathrm{c}}\right)$. Thus, it was necessary to reconstruct the total population from this recall sample in order to estimate the distribution of levels of $\mathrm{HbA}_{1 \mathrm{c}}$ in the genera] population. After stratifying by sex and 10-year age groups, the expected distribution of $\mathrm{HbA}_{1 \mathrm{c}}$ in the population from which the recall sample was drawn was calculated for each age-sex stratum by weighting the numbers in each recall group by the inverse of the sampling fraction and attendance rate for that recall group. Since no men aged over 70 with both glycohaemoglobin and $2 \mathrm{~h}$ blood glucose below the 50th centile attended for recall, this stratum has been excluded from the case-control analysis, leaving 304 cases; however, in order to test the model we have also recalculated relative risk by inclusion of a theoretical additional subject in this group to see whether excluding this stratum from the control data distorts the figures for relative risk. Point and interval estimates of the relative risk for the two highest $\mathrm{HbA}_{1 \mathrm{c}}$ bands combined, versus the lowest, were obtained by a modified version of Woolf's method [21]. Details are given in the Appendix. Because of lack of data, this method has not been used to calculate separate relative risks for subjects in the two highest $\mathbf{H b A}_{1 \mathrm{c}}$ bands. Instead, the number of cases expected in each $\mathrm{HbA}_{1 \mathrm{c}}$ band has been calculated by indirect standardisation from the reconstructed population distribution: the resulting estimates of relative risk are imprecise because of the small numbers of controls.

The hospital diabetic clinic serves a population some 3-fold larger than the district acute services catchment population, and many patients are referred back to the hospital for all acute illness. Because referral patterns for patients with known diabetes may be different from those for non-diabetic patients with AMI [5], no attempt has been made to calculate relative risk of admission for these subjects. Moreover, because subjects dying before admission to hospital were not studied, no estimate of the relative risk of sudden death could be made in any group.

\section{Results}

The numbers of patients admitted with AMI and the frequencies of death and pump failure, unadjusted for age and sex, in different $\mathrm{HbA}_{1 \mathrm{c}}$ bands and in patients with known diabetes are shown in Table 1. Also shown in Table 1 are the age-and-sex-adjusted rates of hospital mortality and of pump failure according to $\mathrm{HbA}_{1 \mathrm{c}}$ group. As previously reported [8] there is a stepwise increase in the incidence of pump failure with increasing levels of glycohaemoglobin although the increase in case fatality is seen only in the highest band of $\mathrm{HbA}_{1 \mathrm{c}}$. Among those in the highest $\mathrm{HbA}_{1 \mathrm{c}}$ band, 5 of the 6 women and 5 of the 11 men died.

Among the 397 subjects without known diabetes, the relative risk of admission and of hospital death after AMI relative to population controls are shown in Table 2. The separate estimates of relative risk in the 2 highest bands of $\mathrm{HbA}_{1 \mathrm{c}}$ are based on small numbers in the original recalled population sample but have been included to show the trends. A stepwise increase in relative risk of admission with AMI with increasing $\mathrm{HbA}_{1 \mathrm{c}}$ is seen. Testing the model by the inclusion of an additional control subject in the males aged $70+$ stratum does not produce any stubstantial alteration of the 
Table 1. Numbers of cases and incidence of pump failure and hospital mortality. Odds ratios are given with $95 \%$ confidence intervals

\begin{tabular}{|c|c|c|c|c|}
\hline $\mathrm{HbA}_{1 \mathrm{c}}$ & $<6.9$ & $6.9-7.8$ & $>7.8$ & $\begin{array}{l}\text { Known } \\
\text { diabetes }\end{array}$ \\
\hline Numbers & 311 & 69 & 17 & 66 \\
\hline Age (SD) & $64.9(11.9)$ & $67.6(9.4)$ & $66.7(8.9)$ & $65.4(11.4)$ \\
\hline Males & $225(78 \%)$ & $54(78 \%)$ & $11(65 \%)$ & $45(68 \%)$ \\
\hline Deaths $(\%)$ & $74(24 \%)$ & $20(29 \%)$ & $10(59 \%)$ & $27(41 \%)$ \\
\hline $\begin{array}{l}\text { Age-sex- } \\
\text { adjusted (\%) }\end{array}$ & $24 \%$ & $28 \%$ & $53 \% 0^{\mathrm{b}}$ & $38 \% \%^{\mathrm{a}}$ \\
\hline Odds ratio & 1.0 & 1.1 (CI0.6-2.6) & 2.0 (CI1.1-2.8) & $2.1($ CI1.1-3.7) \\
\hline Pump failure (\%) & $65(21 \%)$ & $27(39 \%)$ & $9(53 \%)$ & $30(45 \%)$ \\
\hline $\begin{array}{l}\text { Age-sex- } \\
\text { adjusted (\%) }\end{array}$ & $21 \%$ & $35 \%{ }^{\mathrm{b}}$ & $52 \% 0^{\mathrm{b}}$ & $44 \% \%^{\mathrm{c}}$ \\
\hline Odds ratio & 1.0 & 1.4 (CI1.2-4.1) & $2.0(1.1-2.8)$ & $3.1(\mathrm{Cr} 1.8-5.3)$ \\
\hline
\end{tabular}

${ }^{\mathrm{a}} p<0.05 ;{ }^{\mathrm{b}} p<0.01 ;{ }^{\mathrm{c}} p<0.001$ compared with lowest $\mathrm{HbA}_{1 \mathrm{c}}$ level

Table 2. Relative risks of admission and death at different levels of $\mathrm{HbA}_{1 \mathrm{c}}$ relative to population controls. Relative risks are given with 95\% confidence intervals where estimable

\begin{tabular}{|c|c|c|c|}
\hline $\mathrm{HbA}_{1 \mathrm{c}}$ & $<6.9 \%$ & $6.9-7.8 \%$ & $>7.8 \%$ \\
\hline \multicolumn{4}{|c|}{ Acute myocardial infarction admissions } \\
\hline Observed & 243 & 48 & 13 \\
\hline Expected & 280.4 & 19.8 & 3.8 \\
\hline \multirow[t]{2}{*}{ Relative risk } & 1.0 & $\underbrace{2.8}$ & 3.9 \\
\hline & & \multicolumn{2}{|c|}{$3.1(\mathrm{CI} 1.4-6.8)$} \\
\hline \multicolumn{4}{|c|}{ Hospital Deaths } \\
\hline Observed & 53 & 12 & 7 \\
\hline Expected & 64.5 & 6.9 & 0.54 \\
\hline \multirow[t]{2}{*}{ Relative risk } & 1.0 & 2.1 & 15.8 \\
\hline & & \multicolumn{2}{|c|}{$5.3(\mathrm{CI} 2.1-13.4)$} \\
\hline
\end{tabular}

results (relative risks for admission 2.3 for $\mathrm{HbA}_{1 \mathrm{c}}$ 6.9-7.8\%, and 3.6 for $\mathrm{HbA}_{1 \mathrm{c}}>7.8 \%$; for hospital death 2.0 and 11.4 respectively).

\section{Discussion}

The Framingham study [1] showed that the incidence and case fatality of AMI were both increased in subjects with diabetes, and these findings were confirmed in the Israel Ischaemic Heart Disease Study [22]. In these studies there was an increase both in sudden death and hospital fatality in diabetic patients with AMI. By its nature, our study has permitted an assessment of relative risks of admission and of hospital case fatality only for those subjects surviving to be admitted to hospital, who probably represent only around half to three quarters of all patients sustaining AMI [23, 24]. However by the use of a glycohaemoglobin assay, we were able to obtain estimates of relative risk for subjects with previously undiagnosed, as well as known, diabetes.

A major limitation of this study methodology is the inability to standardise between diabetic patients and control subjects for the major risk factors of blood pressure and serum lipids. Because of the lack of observations on these variables in the case series before admission, we have not attempted to standardise for smoking and other risk factors such as body weight. It is possible, therefore, that the observed relationship between levels of glycohaemoglobin and both admission with, and fatality from, myocardial infarction, are the result of associations between these levels and other risk factors.

Our study suggests that the increased mortality in subjects with known diabetes and with clearly elevated levels of glycohaemoglobin results from both an increased incidence of myocardial infarction and an increased case fatality. However, there was no significant increase in hospital case fatality for patients with borderline abnormal levels of glycohaemoglobin. In this population the estimated prevalence of undiagnosed diabetes with fasting hyperglycaemia is approximately $1 \%$ but such subjects contribute $4.3 \%$ of the hospital admissions with, and $9.6 \%$ of hospital deaths from, myocardial infarction.

These results further suggest that hospital case fatality from myocardial infarction is similar in known and in previously undiagnosed diabetic patients. We have separately reported that among diabetic patients there is no relationship between duration of diabetes and hospital case fatality [25], although in the same study we reported an excess risk of admission with myocardial infarction within 5 years of diagnosis of diabetes. Three population studies have addressed the question of mortality of subjects with newly diagnosed, and with known, diabetes. Although the Whitehall Study [2] demonstrated a higher 71/2 year mortality from coronary heart disease in newly diagnosed subjects than in those with known diabetes, the Israel Heart Disease Study [22] found a similar incidence of myocardial infarction and of cardiovascular mortality in those with newly diagnosed and known diabetes. Panzram and Ruttmann have has also reported no difference in vascular mortality between patients diagnosed at screening and those diagnosed, presumably at a later stage, by routine clinical procedures [26]. These findings would tend to suggest that the correction of the haematological and biochemical abnormalities of untreated diabetes do little to reverse the cardiovascular risk of non-insulin dependent diabetes [3, 27]. 
The mechanism of the excess case fatality of diabetic patients after myocardial infarction is not known. We [25] and others [28] have found no difference in infarct size between diabetic patients and non-diabetic subjects although one report suggests that patients with diabetes may have larger infarcts [29]. We have also found no evidence in diabetic patients of an increase in reciprocal electrocardiographic ST segment depression in non-infarcted areas of the heart, an index of ischaemia in these areas [30]. The excess mortality relates solely to pump failure, to which the metabolic effects of insulin deficiency may contribute [31, 32]. A number of reports have attempted to define the benefits of tight blood-glucose control after myocardial infarction [6, $33,34]$ and one study has suggested a benefit [6]. Nevertheless, a larger study with a concurrent control group would be necessary to confirm such a hypothesis.

\section{Appendix}

Suppose that the population from which the control subjects are sampled has size $\mathrm{N}$ and that the control subjects are chosen using a stratified random sample according to $\mathrm{k}$ levels of a factor, $\mathrm{B}$, in this study blood glucose and glycohaemoglobin at screening. This factor may be correlated with the exposure of interest, in this instance $\mathrm{HbA}_{1 \mathrm{c}}$. The form of the data collected is as follows:

\begin{tabular}{lrrrl}
\hline & & \multicolumn{2}{c}{ Exposure } & $\begin{array}{l}\text { Sampling fraction used } \\
\text { in control population }\end{array}$ \\
\cline { 3 - 4 } & & + & - & \\
\hline Cases & & $\mathrm{a}$ & $\mathrm{b}$ & - \\
Control & $\mathrm{B}_{1}$ & $\mathrm{c}_{1}$ & $\mathrm{~d}_{1}$ & $\mathrm{f}_{1}$ \\
subjects & $\mathrm{B}_{2}$ & $\mathrm{c}_{2}$ & $\mathrm{~d}_{2}$ & $\mathrm{f}_{2}$ \\
& $\cdot$ & $\cdot$ & $\cdot$ & $\cdot$ \\
& $\cdot$ & $\cdot$ & $\cdot$ & $\cdot$ \\
& $\cdot$ & $\cdot$ & $\cdot$ & $\cdot$ \\
& $\mathrm{B}_{\mathrm{k}}$ & $\mathrm{c}_{\mathrm{k}}$ & $\mathrm{d}_{\mathrm{k}}$ & $\mathrm{f}_{\mathrm{k}}$
\end{tabular}

In the total control population, expected proportion exposed, $p_{o}=\frac{1}{N} 2 \sum_{i=1}^{k}\left(c_{i} / f_{i}\right)$ and the variance of $p_{o}$ is given by $v\left(p_{0}\right)=\frac{1}{N} 2 \sum_{i=1}^{k} \frac{c_{i} d_{i}}{f_{i}^{2}\left(c_{i}+d_{i}\right)}$.

The relative risk, $R$, can now be estimated using $R=\frac{a / b}{p_{0} /\left(1-p_{0}\right)}$. The variance of the logarithm of the relative risk, $\mathrm{V}(\operatorname{lnR})$ is obtained using $\mathrm{V}(\ln R)=$ $\frac{1}{\mathrm{a}}+\frac{1}{\mathrm{~b}}+\frac{\mathrm{V}\left(\mathrm{p}_{\mathrm{o}}\right)}{\left[\mathrm{p}_{\mathrm{o}}\left(1-\mathrm{p}_{\mathrm{o}}\right)\right]^{2}}$

If the data are stratified, for example by age and sex, then the logarithm of the relative risks and its variance may be calculated within each stratum. An over- all estimate may be obtained by calculating a weighted average of these stratum specific estimates using the inverse of the variances as weights in the usual way.

Acknowledgements. We would like to thank the medical and nursing staff of the Whittington Hospital and the doctors, staff and patients of the St.John's Way Medical Centre, London, for help in performing this study. We are grateful to Mr. M. Shipley who provided valuable statistical advice and to Mr. D. Wilsher for statistical analyses. PMM is a Wellcome Training Fellow in Clinical Epidemiology. GAO was a Novo Research Fellow during the period of this study. RDF and CAJ were supported by grants from the Wellcome Trust and the North East Thames Regional Health Authority. Servier Laboratories Ltd provided support for the glycohaemoglobin assays in the Islington Diabetic Survey.

\section{References}

1. Garcia MJ, McNamara PM, Gordon T, Kannel WB (1974) Morbidity and mortality in diabetics in the Framingham population. Sixteen year follow-up study. Diabetes 23: 105-111

2. Fuller JH, Shipley MJ, Rose G, Jarrett RJ, Keen H (1980) Coronary heart disease risk and impaired glucose tolerance. The Whitehall Study. Lancet I: 1373-1376

3. Panzram G (1987) Mortality and survival in Type 2 (non-insulindependent) diabetes mellitus. Diabetologia 30:123-131

4. Pyörälä K, Laasko M (1983) Macrovascular disease in diabetes mellitus. In: Mann JI, Pyörälä K, Teuscher A (eds) Diabetes in Epidemiological Perspective. Churchill Livingstone Edinburgh London New York, pp 183-247

5. Gwilt DJ (1984) Why do diabetic patients die after acute myocardial infarction? Practical Diabetes 1 (2): 36-39

6. Clark RS, English M, McNeill GP, Newton RW (1985) Effect of intravenous infusion of insulin in diabetics with acute myocardial infarction. Br Med J 291: 303-305

7. ISIS Steering Committee (1987) Intravenous streptokinase given within 0-4 hours of onset of myocardial infarction reduced mortality in ISIS-2. Lancet I: 502

8. Oswald G, Corcoran S, Yudkin JS (1984) Prevalence and risks of hyperglycaemia and undiagnosed diabetes in patients with acute myocardial infarction. Lancet I: 1264-1267

9. Public Health in Europe 5 (1976) Myocardial infarction community registers. Annexe 1. WHO Regional Office for Europe, $\mathrm{Co}-$ penhagen

10. World Health Organisation Study Group Report (1985) Diabetes Mellitus. World Health Organisation Technical Report Series No 727. WHO, Geneva

11. Mortensen HB (1980) Quantitative determination of haemoglobin $A_{1 C}$ by thin layer isoelectric focussing. I Chromatogr 182: 325-333

12. Forrest RD, Jackson CA, Yudkin JS (1986) Glucose intolerance and hypertension in North London: the Islington Diabetes Survey. Diabetic Medicine 3: 338-342

13. Office of Population Censuses and Surveys (1982) Small Area Statistics of the 1981 National Census. OPCS, London

14. Registrar General (1970) Classification of occupations. HMSO, London

15. Menard L, Dempsey ME, Blankstein LA, Aleyassine H, Wacks M, Soeldner JS (1980) Quantitative determination of glycosylated hemoglobin $\mathrm{A}_{1}$ by agar gel electrophoresis. Clin Chem 26: $1598-1602$

16. Forrest RD (1986) Screening for diabetes mellitus: evaluation of glycohaemoglobin assays as screening tests. The Islington diabetes survey. MD thesis to the University of London

17. Forrest RD, Jackson CA, Casburn-Budd M, Taylor JE, Gould BJ, Yudkin JS (1987) Short-term effect of $75 \mathrm{~g}$ oral glucose on glycohaemoglobin levels. Ann Clin Biochem 24: 53-57 
18. Oswald GA, Yudkin JS (1987) Hyperglycaemia following acute myocardial infarction: the contribution of undiagnosed diabetes. Diabetic Medicine 4: 68-70

19. Mantel N, Haenszel W (1959) Statistical aspects of the analysis of data from retrospective studies of disease. J Natl Cancer Inst 22: 719-748

20. Miettinen OS (1976) Estimability and estimation in case-referent studies. Am J Epidemiol 103: 226 235

21. Woolf B (1955) On estimating the relationship between blood group and disease. Ann Human Genet 19: 251-253

22. Herman JB, Medalie, JH, Goldbourt U (1977) Differences in cardiovascular morbidity and mortality between previously known and newly diagnosed adult diabetics. Diabetologia 13: 229-234

23. Mathewson ZM, McCloskey BG, Evans AE, Russell CJ, Wilson C (1985) Mobile coronary care and community mortality from myocardial infarction. Lancet I: 441-444

24. Tunstall Pedoe H, Clayton D, Morris JN, Bridges W, McDonald L (1975) Coronary heart attacks in East London. Lancet I: $833-838$

25. Yudkin JS, Oswald GA (1988) Determinants of hospital admission and case fatality in diabetic patients with myocardial infarction. Diabetes Care (in press)

26. Panzram G, Ruttmann B (1978) Prognose des Diabetes mellitus nach Frühdiagnose durch Glycosurie-Screening. Schweiz Med Wochenschr 108: 221-225

27. Jarrett RJ (1984) Type 2 (non-insulin-dependent) diabetes mellitus and coronary heart disease - chicken, egg or neither? Diabetologia 26: $99-102$

28. Gwilt DJ, Petri M, Lewis PW, Nattrass M, Pentecost BL (1985) Myocardial infarct size and mortality in diabetic patients. $\mathrm{Br}$ Heart J 54: 466-472
29. Rennert G, Saltz-Rennert H, Wanderman K, Weitzman S (1985) Size of acute myocardial infarcts in patients with diabetes mellitus. Am J Cardiol 55: 1629-1630

30. Oswald GA, Corcoran JS, Patterson DLH, Yudkin JS (1985) The extent of coronary artery disease in diabetic patients with myocardial infarction: an ECG study. Diabetic Medicine 3: 541-544

31. Taegtmeyer H, Passmore JM (1985) Defective energy metabolism of the heart in diabetes. Lancet I: 139-141

32. Uusitupa M, Siitonen O, Aro A, Korhonen T, Pyörälä K (1983) Effect of correction of hyperglycaemia on left ventricular function in non-insulin-dependent (type 2) diabetics. Acta Med Scand 213: 363-368

33. Gwilt DJ, Petri M, Lamb P, Nattrass M, Pentecost BL (1984) Effect of intravenous insulin on mortality among diabetic patients after myocardial infarction. Br Heart J 51: 626-630

34. Husband DJ, Alberti KGMM, Julian DG (1985) Methods for the control of diabetes after acute myocardial infarction. Diabetes Care 8: 261-267

Received: 22 June 1987

and in revised form: 22 January 1988

\section{Dr. J.S. Yudkin}

Academic Unit of Diabetes and Endocrinology

Whittington Hospital

Archway Road

London N19 5NF

UK 